\title{
Modeling the process of innovative transformations at the industrial enterprise
}

\author{
Vladimir Patrushev ${ }^{1 *}$, and Victor Popov ${ }^{2}$ \\ ${ }^{1}$ Sorbent JSC, 6, Galperina Street, Perm, 614042, Russia \\ ${ }^{2}$ Department of Management and Marketing, Perm National Research Polytechnic University, 29, Komsomolskiy Prospect, Perm, \\ 614990, Russia
}

\begin{abstract}
The process of innovative transformations at an industrial enterprise is studied. The main features of the introduction of innovations into the production process are considered. A general model for carrying out innovative transformations at an industrial enterprise with a large share of high-tech production is proposed. The main elements of the proposed three-dimensional model include the basic processes of change, project and innovation management. Additionally, the models include such processes as: increasing innovation potential, improving internal communications through the introduction of digital technologies, increasing the efficiency of the production process by improving the production system. The applicability of the proposed model under real production conditions is investigated on the basis of Sorbent JSC, and the impact of the implementation of the innovation process on the overall economic efficiency of the enterprise is assessed.
\end{abstract}

\section{Introduction}

The continuous struggle to increase the economic efficiency of production is one of the foundations that can ensure high competitiveness, profitability and, as a result, the stability of the company. As international practice shows, in a modern economy characterized by increased competition, globalization and instability of sales markets, an effective strategy for increasing production efficiency is the introduction of innovations [1]. Hereinafter, the term innovation will mean any product or process introduced or implemented at an enterprise and leading to a significant improvement in the quality of an already produced product (or service), an increase in the efficiency of production processes, or the release of a completely new product with consumer properties different from previous ones [2]. Below are some examples showing the success of different companies through innovation:

1. Asian consumer electronics manufacturers such as Samsung Electronics Co., Ltd. are good examples of innovation to improve product quality. Until a few decades ago, Samsung Electronics was a domestic manufacturer, practically unknown outside of South Korea. The company's product line consisted of several dozen names, but their quality was low. However, the implementation of systemic reforms within the company in the late $90 \mathrm{~s}$, aimed at reducing the range of products while improving its quality, brought Samsung Electronics into the ranks of the world leaders in the production of electronic household products.

2. An innovative approach to improving the efficiency of production processes is clearly visible by the example of North American car manufacturers (General Motors, Ford Motor Company, Tesla, Inc. and others). Here, thanks to the robotization of production lines, it was possible to organize the production process in 24/7 mode with a small proportion of defective products and a reduction in human resources involved in production. As a result, a $30 \%$ increase in productivity and up to $50 \%$ reduction in production costs for automotive companies was achieved, which significantly increased the competitiveness of these companies in the global market.

3. And finally, an example of innovation for launching a completely new product is Apple Inc., which released in the early 2000 s a number of unparalleled products and services that did not exist in the consumer electronics and music industries. As well, they created a niche of wearable electronics. As a result of the successful implementation of the innovation policy, the capitalization of Apple Inc. exceeded \$1.044 trillion, which made it the most valuable public company in human history.

"Corresponding author: patrushev94@yandex.ru 
The development of innovative production is an expensive and laborious process associated with high risks. At the same time, if successfully implemented it is innovation that can bring companies huge profits that are not available with the traditional material method of production or concentration of finance. That is why the economies of most of the so-called developed countries are essentially innovative, that is, economies based on constant technological improvement with the predominance of high-tech products in production and export. The added value of such products, as well as the technologies for their production, is very high, and the profit is created mainly due to the knowledge and skills of technologists and scientists. A good example is the economies of Japan, the United States and Germany, where spending on research and development of new technologies is about $2.7-3.5 \%$ of GDP [3]. At the same time, the share of these countries in the total export trade of high-tech products in the world market is 39\% for the United States, 30\% for Japan and $15 \%$ for Germany [3].

At the same time, the share of innovative production in Russia is still not large enough and lags far behind in terms of GDP expenditures on science-intensive developments and research and the share of exports of high-tech products from the countries listed above - leaders in introducing innovations into industrial production. Thus, according to Ref. [4], Russia's share of high-tech products in the world market is no more than $0.3 \%$. At the same time, spending on research and development and innovation in Russia is about $1 \%$ of GDP [5]. That is why the modernization of the Russian economy, aimed at increasing the innovative component of industrial production, is one of the priority tasks facing us at the present time.

The purpose of this work is to model the process of introducing innovative transformations at a Russian industrial enterprise with high scientific and technical potential and its own industrial production. Also, the work evaluates the effectiveness of the proposed model in a real production process by the example of the company Sorbent JSC, located in the city of Perm. The period from December 2017 to December 2018 is considered. Based on the results of comparing real production indicators at the enterprise of Sorbent JSC with the expectations obtained in the modeling process, it is concluded that the proposed model is highly effective for the given type of enterprises.

\section{Model description}

Let us consider a general model for carrying out innovative transformations in an industrial enterprise, highlighting the main elements of the model, as well as the processes that must be taken into account when using this model in real production conditions. An important quality of a correctly constructed model is its generality, achieved by highlighting and taking into account the most important parameters and properties corresponding to real systems and, at the same time, ignoring all insignificant details making the research process more complex, but at the same time not significantly affecting the final result of modeling. In this case, the model must satisfy the following requirements: the correspondence of the model to the original (real) system in terms of the bundle of the most important qualities and characteristics, such as: universality, that is, the applicability of the model to the analysis and description of systems of the same type, which makes it possible to expand the application area of the model; accuracy, which characterizes the degree of coincidence of the data obtained during the simulation with the desired results.

Let us represent the general model of innovative transformations at a manufacturing enterprise as a combination of the following elements: analysis of the needs of the consumer market; research and development; prototype design and testing; improvement of production; marketing and sales [6]. In this case, the model implies a parallel arrangement of the listed elements in which several processes can occur simultaneously [7]. So, for example, the process of conducting scientific research occurs simultaneously with testing and improving production, the analysis of market needs does not stop even at the stage of selling the finished product. In addition, the model implies the existence of feedbacks connecting various elements (for example, market analysis and product implementation), which are at the same time the elements of accounting the constantly changing needs of the consumer (Figure1).

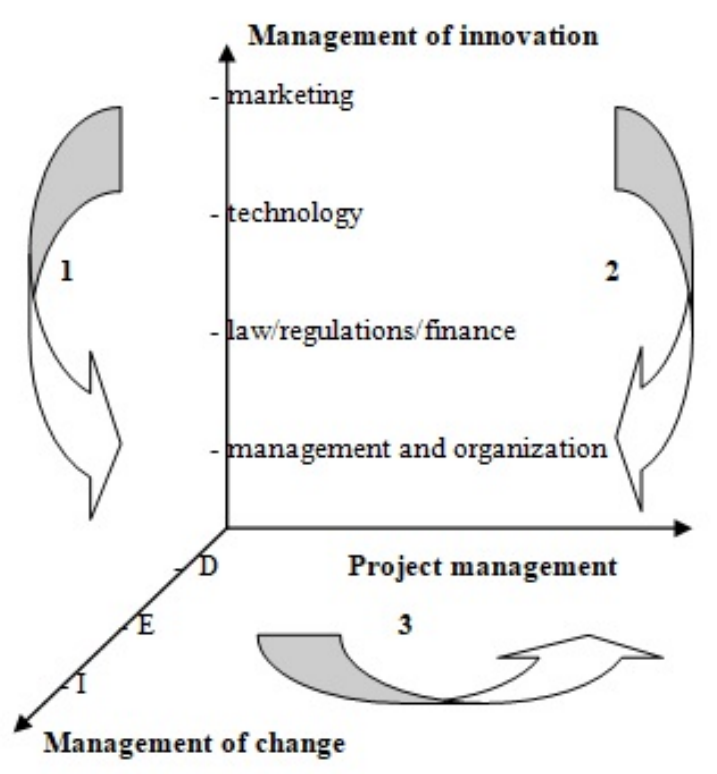

Figure 1. Model of the process of innovative transformations: D - diagnostics; E - engineering; I implementation. Here, 1 - improvement of communications; 2 - improvement of the production system; 3 - development of the innovative potential of personnel. 
The model implies the creation of integrated product teams at the enterprise engaged in continuous analysis of the market for consumer goods and services, analysis of the internal characteristics of the enterprise, its production and scientific and technical potential, the availability of reserves and risks from innovative transformations, project management [8]. The model also implies the presence of processes for the recruiting and training of scientific personnel, designers, innovators, etc., planning a long-term personnel policy designed to ensure the continuity of the knowledge transfer process, selection of equipment and equipping laboratories and research centers. The model includes the production processes of the final product, as well as the search for optimal production parameters that ensure minimum production losses and, as a result, the optimal ratio between the cost of resources and time, on the one hand, and the quality and volume of production, on the other hand [9]. The model contains communication technologies, both within the company and in interaction with the external environment. The effectiveness of the implementation of the proposed model directly depends on the speed and volume of information transmitted between individual elements. Any disruption to the flow of information as a result of loss, distortion or delay of data entails additional losses in production due to underproduction or overproduction of the product, errors in strategic planning and/or scientific and technical research [10]. Here we emphasize the importance of the implementation and use of digital technologies (the socalled digitalization) as one of the components in increasing the efficiency of communication. At the same time, digitalization here does not mean a simple transfer of analog information to digital, but the creation of a fundamentally new, more efficient model for receiving, transmitting and storing information. As one of the components of the enterprise digitalization process, we note the development and implementation of artificial intelligence and machine learning technologies. These technologies, which have become widespread in recent years, can replace people in many processes related to the collection and analysis of information and promise in the coming years to revolutionize the tools available to companies for analyzing sales markets, optimization, forecasting and planning development strategies.

\section{Results and discussion}

An important part of this study is the use of the proposed model in real production conditions, as well as the assessment of the impact of the introduction of the innovation process on the overall economic efficiency of the enterprise. The company Sorbent JSC, located in the city of Perm, was chosen as a testing ground for validation the model of innovative transformations. Founded in 1939 as a plant for the production of activated carbon, the company Sorbent JSC is currently the largest developer and manufacturer of personal respiratory protection in the
Russian Federation. The company also produces various types of activated carbon (more than 40 items), coagulants and systems for drinking water purification. The peculiarities of the enterprise include the presence of both its own scientific and technical and production lines. At the time of this study, the staff of the enterprise was 1200 people.

In accordance with the model described above, the following actions were carried out at the company Sorbent JSC:

1. Integrated product teams were created to analyze the current state of the enterprise, study the features of the organization of production and develop a strategy for the implementation of innovations. A preliminary analysis of the production process at the enterprise showed the presence of a number of labor-intensive and energy-intensive processes that affect the total production time and lead to noticeable losses. These processes, as a rule, referred to operations and activities based on the use of manual labor. It was also found that the presence of losses does not affect the quality of the final product, but leads to a decrease in the economic efficiency of the enterprise. As a result, the volume of manufactured products is less than the capacities available at the Sorbent JSC enterprise allow. To eliminate the identified production losses at the enterprise, it was decided to introduce an innovative production model based on the concept of lean manufacturing (LM). Here, we note that the choice of this concept is in good agreement with the goals and objectives of the Russian national project "Labor productivity and employment support", approved by the Presidium of the Council under the President of the Russian Federation for Strategic Development and Priority Projects (Minutes No. 12 dated September 24, 2018).

2. Further, diagnostics of all actions and processes that are potential sources of problems were made, the search for solutions aimed at correcting problems and increasing efficiency within the framework of the LM concept. Thus, partial or complete automation of workplaces was carried out, which entailed a significant reduction in the share of manual labor (while maintaining the total number of workplaces). Then the technology of visualization of the production process was introduced and the information centers necessary for this were created. This measure made it possible to create effective channels for control and management of production and management processes, and also ensured quick communication between employees of integrated product teams. 
3. Finally, as a measure to increase production efficiency, a continuous flow of single-piece movement was organized in the finished product assembly areas, which made it possible to reduce the total time of the production process. Also, the storage conditions for finished products and components for their assembly were optimized.

Evaluation of the effectiveness of the innovative processes implemented at the company Sorbent JSC was carried out by comparing the main production indicators in December 2017 (i.e. before the start of the transformations) and in December 2018, when the main innovative elements were introduced into the production process and came into effect. The following indicators were considered: process time (PT), productivity, i.e. the amount of finished products produced by one employee per unit of working time and corresponding to the quality standards adopted at the enterprise and the share of work in progress (WIP). The following results were obtained:

1. As of December 2017, the manufacturing process took an average of 12 days. However, in April 2018, after the start of the innovative transformation program, this figure dropped to 5 days. Subsequently, the reduction in the process time continued and reached the value of 3 days as of December 2018. Thus, the improvement in the PT indicator during the study was $75 \%$.

2. During the same time, there was an increase in productivity from 34 units per person per shift to 60 . In other words, the change over the year was about $76.5 \%$.

3. Also, positive dynamics was observed for the WIP indicator. Here, from December 2017 to December 2018, the reduction in WIP units was 2.75 - 3 times.

It is important to note that the above changes in production figures at Sorbent JSC were achieved as a result of the implementation of only some elements of the model of innovative transformation of enterprises proposed in this article. So, due to the time constraints imposed on this study, we did not investigate the processes of increasing the innovative potential of the enterprise associated with the recruiting and training of personnel, equipment for research and development departments, deep modernization of industrial equipment, and others. It is expected that the implementation of all measures provided by the model in the long term will lead to an even greater increase in the economic efficiency of the enterprise.

\section{Conclusion}

Thus, this work simulates the process of introducing innovative transformations at a Russian industrial enterprise with a high scientific and technical potential and its own industrial production. A system of measures is proposed to improve the efficiency of the production process by: managing changes, projects and innovations, increasing innovative potential, improving internal communications through the introduction of digital technologies, increasing the efficiency of the production process by improving the production system. Testing the model at the production facilities of Sorbent JSC shows the high efficiency of the proposed model. It was found that the implementation of innovative transformations in the production process at enterprises led to a $75 \%$ improvement in the time of manufacturing a product, as well as productivity value per employee per shift. At the same time, the share of work in progress decreased three times.

\section{References}

1. J. Schumpeter, The theory of economic development. (M.: Eksmo, 2007)

2. R. Boutellier, O. Gassmann, M. von Zedtwitz, Managing Global Innovation: Uncovering the Secrets of Future Competitiveness (3rd ed., Springer, 2008)

3. Research and development management in Russian companies. National report (Moscow: HSE University, 2011)

4. Science. Innovation. Information society. Brief statistical collection (M.: HSE University, 2009)

5. Science of Russia in Figures, 2010 (M.: TsISN, 2010)

6. GOST 57313-2016 Innovation management. Innovation Management Guide. (Moscow: Standartinform)

7. British Standard: 03.100.01 Design management systems. Guide to managing innovation ICS (2008)

8. A guide to the project management body of knowledge (PMBOK $®$ Guide) $\left(5^{\text {th }}\right.$ ed., Newtown Square, PA: Project Management Institute, 2013)

9. V. Popov, G. Ostapenko, Management Mechanism for Implementation of Quick Response Manufacturing Concept the Enterprise, Proc. $4^{\text {th }}$ Int. Conf., Prague, University of Economics in Prague (2016)

10. V.S. Patrushev, V.L. Popov, Bull. PNRPU. Soc.econ. sci. 2, 208 (2020) 